\title{
Insecticide resistance and size assortative mating in females of the maize weevil (Sitophilus zeamais)
}

\section{Erick Mauricio G Cordeiro, ${ }^{\mathrm{a}, \mathrm{b}, \mathrm{c}}$ Alberto S Corrêa, ${ }^{\mathrm{c}}$ Conrado A Rosi-Denadai, ${ }^{\mathrm{a}}$ Hudson Vaner V Toméa and Raul Narciso C Guedes ${ }^{\mathrm{a}^{*}}$}

\begin{abstract}
BACKGROUND: Random mating is a common assumption in studies of insecticide resistance evolution, but seldom tested despite its potential consequences. Therefore, the existing evidence of female choice and insecticide resistance in populations of the maize weevil (Sitophilus zeamais), a key pest of stored cereals, led to the assessment of mating preferences and their association with insecticide resistance in this species.

RESULTS: Mixed lines of a maize weevil colony were established from field-collected populations, which after 5 months of natural breeding were selected for deltamethrin resistance for five generations, reaching over 100-fold resistance. Mating preference was significantly based on the partner size, measured as body mass $\left(\chi^{2}=5.83, \mathrm{df}=1, P=0.016\right)$. Susceptible females preferred heavier males for mating $\left(\chi^{2}=5.83, \mathrm{df}=1, P=0.015\right)$, a trait that was more frequently associated with deltamethrin resistance $\left(\chi^{2}=7.38, \mathrm{df}=1, P=0.007\right)$. Deltamethrin resistance compromised daily fertility, although the reduced offspring production observed in matings between susceptible females and resistant males was negligible.
\end{abstract}

CONCLUSION: Susceptible female weevils prefer larger (and heavier) males to mate, a trait associated with deltamethrin resistance, favouring the maintenance and spread of the resistant phenotype in the population.

(c) 2016 Society of Chemical Industry

Keywords: pyrethroid resistance; female mating preference; stored-maize pests; fitness cost; mate choice; deltamethrin

\section{INTRODUCTION}

Insecticide resistance and assortative mating are two phenomena rarely considered together, although the latter is a pest biology trait that potentially affects the evolution of the former. ${ }^{1,2}$ Assortative mating is a potential consequence of mate choice, which is a target of intensive study and speculation regarding its evolutionary causes. ${ }^{3,4}$ Therefore, the relative neglect of non-random mating owing to mate choice and the potential consequences for the evolution and spread of insecticide resistance is curious, particularly considering that the traits involved in assortative mating are often not correlated with selection for survival, but may affect insecticide control efficacy. ${ }^{1,3-5}$

Random mating is a frequent assumption in models of insecticide resistance evolution, ${ }^{1,6}$ even when individual variation is considered in such models. ${ }^{7,8}$ Nonetheless, this assumption has proved to be faulty in a few instances. Loss of mating competitiveness, for example, may lead to mating disadvantage as a consequence of fitness costs associated with insecticide resistance, which may interfere with mate selection..$^{9-11}$ Mating preferences are simpler to recognise and explain when sex-specific attributes and qualities are evident, such as morphological ornaments and gift provision. ${ }^{4,12}$ Nonetheless, subtle traits and behavioural peculiarities may affect mating behaviour and evolution of resistance to insecticides, ${ }^{13,14}$ which provide a marked contrast to asexual organisms. ${ }^{15}$ In fact, mate selection based on secondary and non-resource-based attributes associated with a hidden quality, such as pesticide resistance, also occurs, although it is usually harder to recognise. ${ }^{5}$

Assortative mating by size (or weight, if used as a surrogate for size) is one of the most prevalent mating patterns among natural populations, including arthropod populations. ${ }^{16}$ This mating pattern is frequently associated with mate choice, although it may also result from greater mate availability and mating constraints relative to size differences between sexes. ${ }^{16,17}$ Furthermore, size assortative mating may also exhibit a marked influence on population demography and genetics., ${ }^{4,16,18}$ Therefore, size assortative mating is potentially relevant for pest management if occurring in association with management-relevant traits in arthropod pest species, ${ }^{4,16,18}$ a possibility that is currently neglected.

* Correspondence to: RNC Guedes, Departamento de Entomologia, Universidade Federal de Viçosa, Viçosa, MG 36570-000,Brazil.E-mail: guedes@ufv.br

a Departamento de Entomologia, Universidade Federal de Viçosa, Viçosa, MG, Brazil

b Department of Entomology, Kansas State University, Manhattan, KS, USA

c Departamento de Entomologia e Acarologia Agrícola, Escola Superior de Agricultura 'Luiz de Queiroz', Universidade de São Paulo (ESALQ-USP), Piracicaba, SP, Brazil 
The potential association of insecticide resistance and assortative mating, or more particularly size assortative mating, is potentially important for pest management in scenarios where size differences exist between insecticide-resistant and insecticide-susceptible arthropod pest populations.

Pyrethroid resistance and associated body mass (and size) variation do exist among strains of the maize weevil, Sitophilus zeamais Motsch. (Coleoptera: Curculionidae), a key pest of stored cereal grains of cosmopolitan distribution. This trait co-occurrence among maize weevil strains and evidence of assortative mating in this species make it a suitable model to test the potential effects of mate choice on insecticide resistance in this weevil. Insecticide resistance among Brazilian populations of the maize weevil have been reported since the early 1990s and remains a problem. ${ }^{19-26}$ Reported differences in body mass (and size), energy metabolism and fluctuating asymmetry (i.e. subtle random deviations from perfect bilateral symmetry, which is frequently associated with mate preference) among maize weevil strains were suggestive of potential sexual selection and consequent assortative mating among them. ${ }^{27-32}$ Male-producing (aggregation) pheromone in grain weevils and the active pursuing of males by female maize weevils also reinforce this expectation. ${ }^{33-35}$ Indeed, a recent study indicated female mating choice in two strains of the maize weevil of distinct genetic background, although the underlying basis of the mate preference was not recognised. ${ }^{36}$ These findings led to the present study aimed at assessing assortative mating in the maize weevil and its potential association with pyrethroid resistance.

We hypothesised that size, measured as body mass of individual insects, may play a relevant role in the mate preference of female weevils, a trait that is also associated with pyrethroid resistance in Brazilian strains of this species. ${ }^{27,28}$ Female choice, but not male choice, was detected in the maize weevil, ${ }^{36}$ and although body mass was unable to explain the choice, only two strains of distinct genetic background were used in this initial study. This potentially compromised the resolution of such detection, which is likely to be aided by other traits, as in cases of lack of sex dimorphism and resource-based selection. ${ }^{5}$ Therefore, a pool of eight distinct field-collected populations exhibiting varying levels of pesticide resistance was used in this study to obtain a deltamethrin-selected strain with the same genetic background of the unselected (thus susceptible) strain. Mating preference and the reproductive output of each cross were also assessed to allow the recognition of any eventual association between insecticide resistance and mate choice with potential fertility consequences.

\section{MATERIALS AND METHODS}

\subsection{Insects}

Twenty pairs of maize weevils (S. zeamais) were randomly obtained from each of eight field-collected populations sampled between 2010 and 2011 and maintained as large laboratory colonies $(<500$ individuals per container) to minimise the loss of genetic variability. These field populations exhibited varying levels of insecticide resistance (mainly pyrethroid resistance, but also organophosphate and phosphine resistance). ${ }^{24,26,27}$ The gathered pairs of each population were subsequently placed together in a $3 \mathrm{~kg}$ transparent glass jar providing a low competition environment without resource limitation. These weevils of different genetic background were allowed free mating for five successive generations (i.e. about 150 days), creating a diverse gene pool from which insecticide-resistant and insecticide-susceptible lines were subsequently branched out. The insect colonies were always maintained within a controlled environmental room at a temperature of $27 \pm 2{ }^{\circ} \mathrm{C}, 70 \pm 10 \%$ relative humidity and a $12: 12 \mathrm{~h}$ photoperiod (L:D).

\subsection{Selection for deltamethrin resistance}

The diverse stock colony was subjected to a concentrationmortality bioassay with the pyrethroid deltamethrin $\left(25 \mathrm{~g} \mathrm{Al} \mathrm{L}^{-1}\right.$ synergised with piperonyl butoxide at $250 \mathrm{~g} \mathrm{Al} \mathrm{L}^{-1}$, emulsifiable concentrate; Bayer CropScience, São Paulo, Brazil). The insecticide was sprayed as a water emulsion at a rate of $1.0 \mathrm{~mL}$ per $500 \mathrm{~g}$ of maize kernels ( $13 \%$ moisture content) placed in a rotatory stainless steel container for homogenisation until the residue dried (about $1 \mathrm{~h}$ later). An artist's air brush (Sagyma SW440A; Yamar Brasil, São Paulo, Brazil) connected to an air pump (Prismatec 131A Tipo 2VC; Itu, São Paulo, Brazil) was used for spraying at $0.7 \mathrm{kgf} \mathrm{cm}^{-2}$ pressure. Four deltamethrin concentrations were used $(0.125,0.25,1.25$ and $2.50 \mathrm{ppm}$ ), in addition to a control treatment where only water was used to correct for eventual natural mortality. The sprayed maize kernels $(15 \mathrm{~g}$ ) were placed into $25 \mathrm{~mL}$ glass vials into which 20 non-sexed adult insects ( $<1$ week old) were released, thus constituting the experimental unit. The upper portion of each vial had its inner walls coated with Teflon ${ }^{\circledR}$ PTFE (DuPont, Wilmington, DE) to prevent the insects from escaping; although the vials were left uncapped, they were covered with organza tissue attached with a rubber band. Five replicates were used for each insecticide concentration, and the vials were maintained under the same controlled conditions as used for the weevil colony maintenance. Weevil mortality was assessed after $24 \mathrm{~h}$ exposure to the dried insecticide residue by prodding each individual with a fine hair brush; the insect was considered to be dead if it was unable to walk the length of its body.

Selection for deltamethrin resistance started after the five generations of free mating on the freely interbreeding stock colony and after characterisation of its deltamethrin susceptibility. This strain was then subjected to five cycles of deltamethrin selection over six consecutive generations of three established selection lines, in opposition to the establishment of three unselected lines derived from the same colony stock. The selection for deltamethrin resistance was carried out by exposing adult weevils to the $\mathrm{LC}_{50}$ estimated for the previous generation and using the surviving individuals to maintain the three independent selected lines. Concentration-mortality bioassays were carried out at each generation, except for $F_{2}$ owing to lack of insects, to characterise its resistance to deltamethrin following the methods previously described. The following concentrations (besides the control) were used for each generational bioassay: $F_{1}-0.125$, $0.250,0.625$ and 1.250 ppm; $F_{3}-0.125,0.250,0.625,1.250$ and 2.50 ppm; $F_{4}-0.625,1.250,2.50,3.75$ and 4.375 ppm; $F_{5}-6.25$, $8.75,12.50$ and $18.75 \mathrm{ppm}$. The unselected lines were sprayed only with water at each generation.

\subsection{Mate choice bioassays}

Dichotomous choice tests were used to test whether there was strain mating preference among the chooser strain and sex using body mass (characterised as either lighter or heavier) of the chosen insects as a covariate surrogate for size. Thus, each newly emerged virgin weevil (one-day-old males and females) was obtained from the selected (or unselected) lines, sexed using respective patterns of rostrum length, texture and punctuation, ${ }^{37,38}$ isolated in $25 \mathrm{ml}$ glass tubes with maize kernels for 3 days (for sexual maturation), 
weighed on an electronic scale (model XS3DU; Mettler Toledo, Columbus, $\mathrm{OH}$ ) and randomly code marked on the thorax using white nail polish to allow recognition of sex and strain before proceeding with the mate choice bioassay. ${ }^{36}$ Each single female or male insect of the deltamethrin-selected or unselected line was placed in a petri dish mating arena $(9.0 \times 0.50 \mathrm{~cm}$, coated with Teflon ${ }^{\circledR}$ PTFE) with two members of the opposite sex and from the two divergent strains used (i.e. deltamethrin selected or unselected), each recognised either as the lighter or the heavier of the possible mating choices. The insects were allowed to mate and followed for $10 \mathrm{~min}$ or until coupling was clearly recognised. ${ }^{35,36}$ Upon mating completion and mate choice recording, the weevils were recovered and placed in individual vials $(25 \mathrm{ml}$ with maize kernels), and the procedure was repeated with the same insects used for each mating bioassay for three consecutive days. At least seven couples for each line and treatment combination were used in these consecutive bioassays.

\subsection{Reproductive output}

The reproductive output of the different mating combinations was assessed using $1 \mathrm{~L}$ glass jars containing $300 \mathrm{~g}$ of maize kernels. Ten pairs of newly emerged weevils ( $<3$ days old) were used from each of the four possible mating combinations [i.e. resistant female and male $\left(q R \times \sigma^{\top} R\right)$, susceptible female and male $\left(\% S \times{ }^{\top} S\right)$, resistant female and susceptible male $\left(Q R \times{ }^{\top} S\right)$ and susceptible female and resistant male $\left.\left(\$ S \times \delta^{\top} \mathrm{R}\right)\right]$. These weevil pairs were released in each jar and removed 28 days later following methods described earlier for this species. ${ }^{39-41}$ The removal of the parental pairs allowed unbiased recording of the offspring of the predetermined mating combinations. The progeny emergence (i.e. fertility) was assessed until no more progeny emerged, some 100 days after the start of the experiment. The experiment was replicated at least 3 times, each one with a set of replicated lines of each diverging strain (i.e. deltamethrin selected and unselected).

\subsection{Statistical analyses}

Concentration-mortality data were subjected to probit analyses (PROC PROBIT, SAS software; SAS Institute, Cary, NC), and 95\% confidence intervals for resistance ratios were estimated following Robertson and Preisler, ${ }^{42}$ and considered to be significant if they did not include the value 1. Logistic regression (PROC LOGISTIC, SAS software; SAS Institute) was used to test whether the strain and sex of the choosing individual, and the body mass (and thus size) of the chosen weevil, may be playing a role in mating selection. The dichotomous results from the mating bioassays were subjected to randomness $\chi^{2}$-test using Yates's correction for continuity. ${ }^{43}$ The relationship between the weevil chooser and the chosen weevil body mass was tested using correlation analysis (PROC CORR, SAS software; SAS Institute). Regression analyses were used to assess the gain by selection with deltamethrin exposure and to model weevil fertility with time (number of adult progeny produced per female) using the curve-fitting procedure of TableCurve 2D (Systat, San Jose, CA). The significant regression models $(P<0.05)$ were always tested from the simplest (linear and quadratic) to more complex models, using parsimony, high $F$-values (and mean squares) and steep increases in $R^{2}$ with model complexity as criteria for model selection; residual distribution was checked to validate parametric assumptions. The overall fertility of each mating type was subjected to a two-way analysis of variance (female and male strain as factors); assumptions of normality and homoscedasticity were checked, and no data transformation was necessary (PROC UNIVARIATE, SAS software; SAS Institute).

\section{RESULTS}

\subsection{Selection for deltamethrin resistance}

Selection for deltamethrin resistance was successfully accomplished within six generations, reaching high levels of resistance (i.e. $>100$-fold) after five cycles of selection (Table 1). The gain by deltamethrin selection was only mild for the four initial generations, but experienced a steep increase with the fifth cycle of selection when compared with the unselected weevil lines (Fig. 1).

\subsection{Mating preference}

The results of the dichotomous free-mating bioassays subjected to logistic regression to test whether mating preference was dependent on the chooser strain and sex, as well as the previous selection and chosen weevil body mass, provided significant results $\left(\chi^{2}=13.99, \mathrm{df}=5, P=0.001\right)$. Previous mate selection did not affect significantly mate choice, nor the strain and sex (besides their interaction) of the chooser weevil, regardless of its sex (Table 2). Nonetheless, the body mass of the chosen mate played a significant role in mating preference (Table 2), although the correlation between chooser and chosen body mass was not significant $(r=0.11, P=0.20, n=144)$. When only male choice was considered, the logistic regression was not significant $\left(\chi^{2}=4.85\right.$, $\mathrm{df}=4, P=0.30)$, unlike when only female choice was considered $\left(\chi^{2}=12.28, \mathrm{df}=4, P=0.01\right)$. Therefore, female mating preference was detected and was significantly affected by the chooser strain and the interaction between chooser strain and chosen body mass $\left(\chi^{2}=5.39, \mathrm{df}=1, P=0.02\right.$ and $\chi^{2}=4.60, \mathrm{df}=1, P=0.03$ respectively). This finding is a likely consequence of the significant association between deltamethrin resistance and heavier insects $\left(\chi^{2}=7.38, \mathrm{df}=1, P=0.007\right)$ (Fig. 2).

\subsection{Size assortative mating}

The preference for heavier (and larger) weevils was subsequently tested on the basis of the strain and sex of the choosing weevil, attempting to provide evidence of possible size assortative mating among weevils and its potential association with pyrethroid resistance. Again, male weevils did not exhibit significant size mating preference $\left(\chi^{2}<1.06, \mathrm{df}=1, P>0.30\right)$, nor did the pyrethroid-resistant females $\left(\chi^{2}=1.04, \mathrm{df}=1, P=0.31\right)$ (Fig. 3). Nonetheless, susceptible female weevils exhibited significant size assortative mating, preferring heavier males as mating partners $\left(\chi^{2}=5.83, \mathrm{df}=1, P=0.015\right)$ (Fig. 3).

\subsection{Reproductive output}

The overall fertility was significant only at $P=0.10$, and only owing to the female strain $\left(F_{1,12}=3.40, P=0.09\right)$, not the male strain $\left(F_{1,12}=0.12, P=0.73\right)$, with matings involving susceptible females (regardless of the male strain) leading to higher overall progeny production $\left(\right.$ o $S \times{ }^{\top} \mathrm{S}$ : $361.00 \pm 39.87$ weevils; OS $\times{ }^{\top} \mathrm{R}: \quad 336.33 \pm 66.51$ weevils; $\mathrm{R} \times{ }^{\top} \mathrm{S}: 284.00 \pm 51.32$ weevils; $\$ R \times \circlearrowleft$ R: $264.00 \pm 33.91$ weevils). More importantly though, the non-cumulative fertility results of the four possible mating combinations provided significant non-linear regression (peak) models with distinct parameters indicating different reproductive outputs for each mating combination (Table 3). Again the effect of female strain was stronger, with susceptible matings leading to higher and earlier fertility peaks, followed by matings between susceptible female and resistant male (Fig. 4). Matings involving resistant females led to lower fertility, particularly when mated with deltamethrin-resistant males, which provided a nearly $30 \%$ 
Table 1. Relative toxicity of deltamethrin throughout five cycles of selection with this insecticide in a mixed population of the maize weevil S. zeamais

\begin{tabular}{|lccccccc} 
Population & Generation & Degrees of freedom & Slope \pm SE & $\mathrm{LC}_{50}(95 \% \mathrm{FL})(\mathrm{ppm})$ & $\mathrm{RR}_{50}(95 \% \mathrm{Cl})$ & $\chi^{2}$ & $P$ \\
\hline Unselected parental & $\mathrm{P}$ & 2 & $1.73 \pm 0.17$ & $0.22(0.17-0.27)$ & $1.00(0.77-1.30)$ & 1.58 & 0.45 \\
Deltamethrin-selected & $\mathrm{F}_{1}$ & 2 & $1.08 \pm 0.23$ & $0.90(0.61-1.80)$ & $4.05(2.59-6.34)$ & 2.43 & 0.30 \\
& $\mathrm{~F}_{3}$ & 3 & $1.39 \pm 0.33$ & $5.64(3.22-22.38)$ & $25.48(9.71-66.87)$ & 5.83 & 0.12 \\
& $\mathrm{~F}_{4}$ & 3 & $1.99 \pm 0.32$ & $4.27(3.46-5.94)$ & $19.32(14.50-25.74)$ & 0.66 & 0.88 \\
& $\mathrm{~F}_{5}$ & 2 & $2.91 \pm 0.62$ & $23.17(18.47-37.68)$ & $104.61(76.85-142.37)$ & 1.34 & 0.51 \\
\hline
\end{tabular}

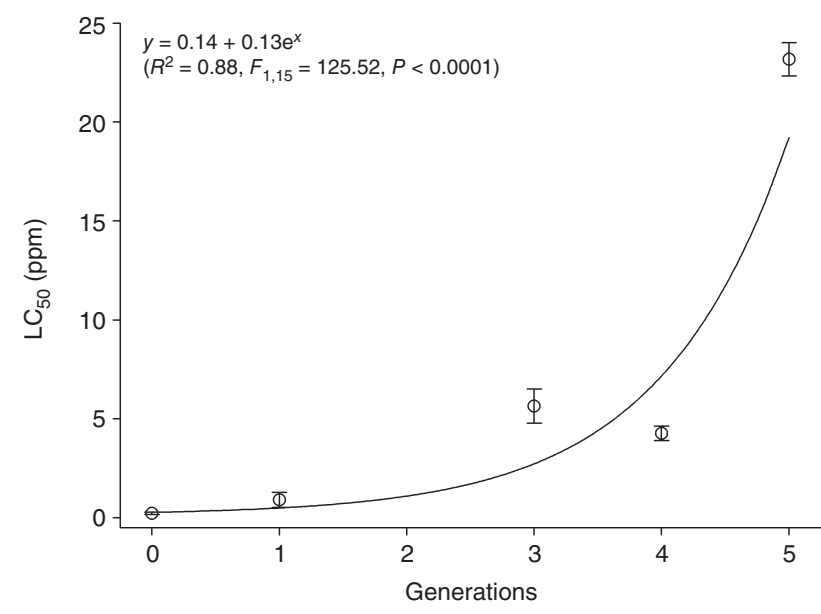

Figure 1. Increase in $\mathrm{LC}_{50}$ for deltamethrin, and thus in deltamethrin resistance, through five cycles of selection of a mixed population of the maize weevil (S. zeamais). Each symbol indicates the mean ( \pm SE) observed values of five replicates.

Table 2. Results of multiple logistic regression analysis exploring the significant contributors for the selection of the strain of the chosen mate among maize weevils (S. zeamais). The model was significant based on the likelihood ratio test statistic $(P<0.05)$

\begin{tabular}{|lrcc|}
\hline Source of variation & Estimate & $\chi^{2}$ & $P$ \\
\hline Previous mating & -0.001 & 0.001 & 0.995 \\
Chooser strain & 0.540 & 1.272 & 0.259 \\
Chooser sex & -0.800 & 1.922 & 0.166 \\
Chooser strain $\times$ chooser sex & 0.306 & 0.168 & 0.681 \\
Chosen body mass & -0.874 & 5.832 & $0.016^{*}$ \\
\hline * Significant difference $(P<0.05)$ & & & \\
\hline
\end{tabular}

lower fertility peak with a nearly 3 day delay compared with the susceptible mating and accounting for a significant demographic impact (Table 3 and Fig. 4).

\section{DISCUSSION}

The potential association between size assortative mating and insecticide resistance was the target of the present study, in which we hypothesised that size, measured as body mass, may be associated with pyrethroid resistance in Brazilian populations of the maize weevil. Variation in body mass and its association with insecticide resistance were previously reported in this species, ${ }^{27,44}$ and a recent study recognised female mating preference in the maize weevil, although the basis of such preference was not detected. ${ }^{36}$ While focusing on deltamethrin-susceptible and

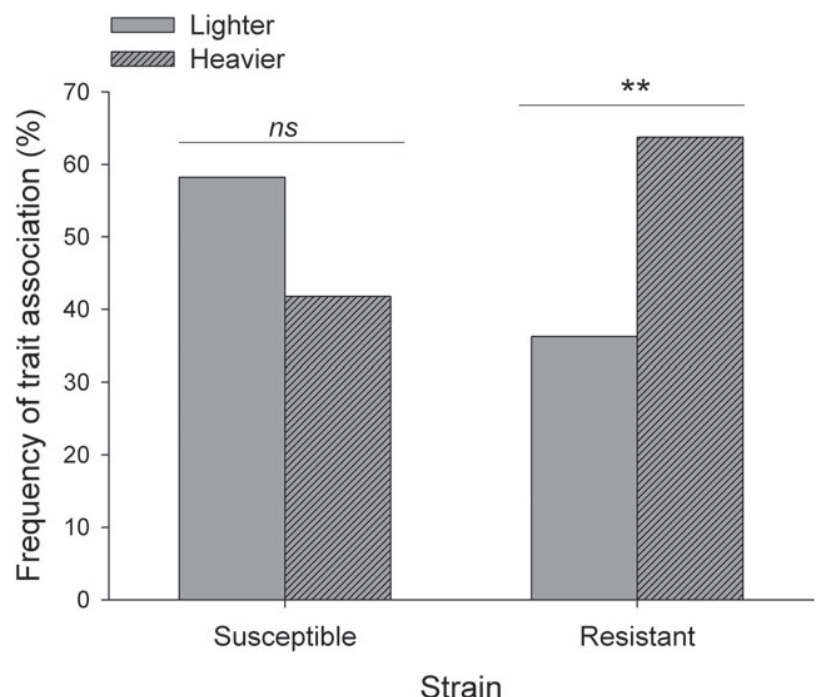

Figure 2. Frequency of incidence of lighter and heavier body mass in deltamethrin-susceptible and deltamethrin-resistant strains of the maize weevil (S. zeamais). The asterisk indicates significant difference $(P \leq 0.01)$ and $n$ indicates a lack of difference $(P>0.05)$ in the incidence of lighter and heavier weevils within each strain by the $\chi^{2}$-test with Yates correction for continuity.

deltamethrin-resistant strains with the same genetic background, unlike in the previous study by Guedes et al., ${ }^{36}$ we were able to detect size assortative mating by the susceptible female weevils, thus favouring matings with deltamethrin-resistant males, which are heavier.

Assortative mating in arthropods can be explained by three non-exclusive hypotheses - mate choice, mate availability and mating constraints. ${ }^{16}$ Mate choice takes place when males, females or both exercise choice, establishing a tendency of one type to pair with another specific type. In contrast, mate availability is based on the tendency of a sex to mate with the more noticeable members of the alternative sex, while mating constraints refer to the reduction in probability or duration of pairing caused by either physical or energetic limitations for courtship, pairing or mating. The lack of correlation between female and male body mass in our study and that of Guedes et al., ${ }^{36}$ which would provide support for the mate availability hypothesis, and the lack of any strong (and general) sexual selection criteria among maize weevils, expected under the mating constraint hypothesis, ${ }^{16,17}$ indicate mate choice as the likely cause of assortative mating in the maize weevil.

There is no shortage of empirical evidence of mate choice, and particularly of female choice, among arthropods. ${ }^{16-18}$ Among insects of stored products, for instance, mutual mate choice was reported in the hide beetle Dermestes maculatus De Geer (Coleoptera: Dermestidae), ${ }^{18}$ and female mating preference was detected in the red flour beetle Tribolium castaneum (Herbst) 


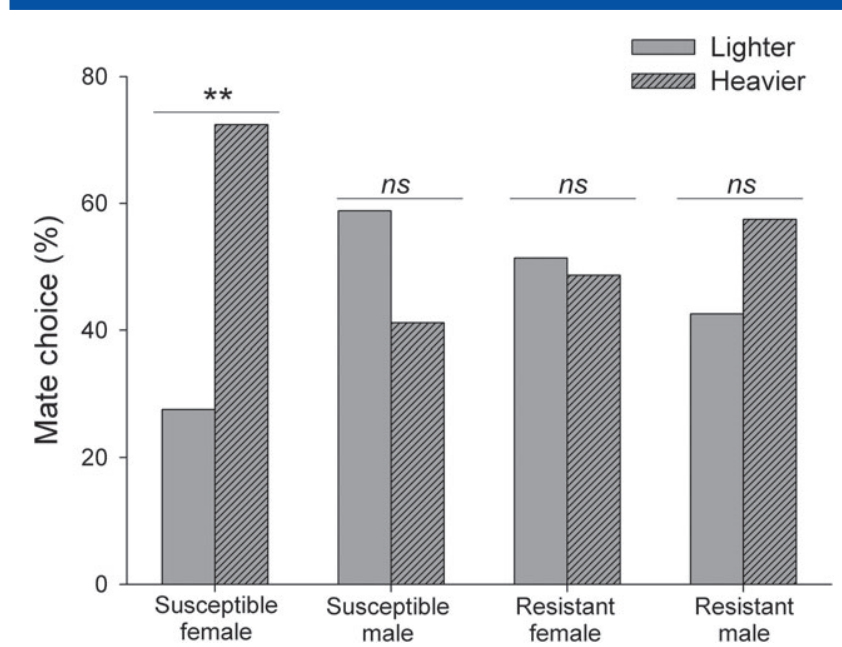

Figure 3. Mate preference for body size (lighter $\times$ heavier) in females and males from deltamethrin-susceptible and deltamethrin-resistant strains of the maize weevil (S. zeamais). The asterisk indicates significant difference $(P \leq 0.01)$ and $n s$ indicates a lack of difference $(P>0.05)$ in the incidence of lighter and heavier weevils within each strain by the $\chi^{2}$-test with Yates correction for continuity.

(Coleoptera: Tenebrionidae). ${ }^{45}$ Thus, the detection of female choice in the maize weevil is not a surprise, despite the common association between female mating preference and elaborate male traits or male resource provision, both of which are apparently absent in grain weevils. ${ }^{35,36,46}$ Female choice may seem more difficult to explain in such circumstances, but not if potential indirect benefits (e.g. without any direct measurable benefits, such as genetic benefits) are considered in addition to direct benefits. ${ }^{4,5}$ Furthermore, the potential occurrence of sensory exploitation (i.e. exploitation of pre-existing biases of the female sensory system), genetic compatibility and sexual conflict (i.e. sexes' incompatible optima) also lent credence to the occurrence of female choice without elaborate male ornaments and resource provision.,4

Assortative mating due to female choice is difficult to demonstrate because the preference may result from a male advantageous trait allowing it to outcompete its rivals, or may be confounded by male-male competition. ${ }^{16}$ Indeed, enhanced male competitiveness has been reported in insecticide-resistant mosquitos and red flour beetles, ${ }^{45,47}$ and may also take place in the maize weevil, particularly if the resistant strain was subjected to extended and intensive selection; ${ }^{36}$ however, this is not the case in the present study and for the selected deltamethrin-resistant strain used here. Male-male competition may also make difficult the detection of female choice leading to assortative mating. However, female weevils actively pursue male weevils [the gender

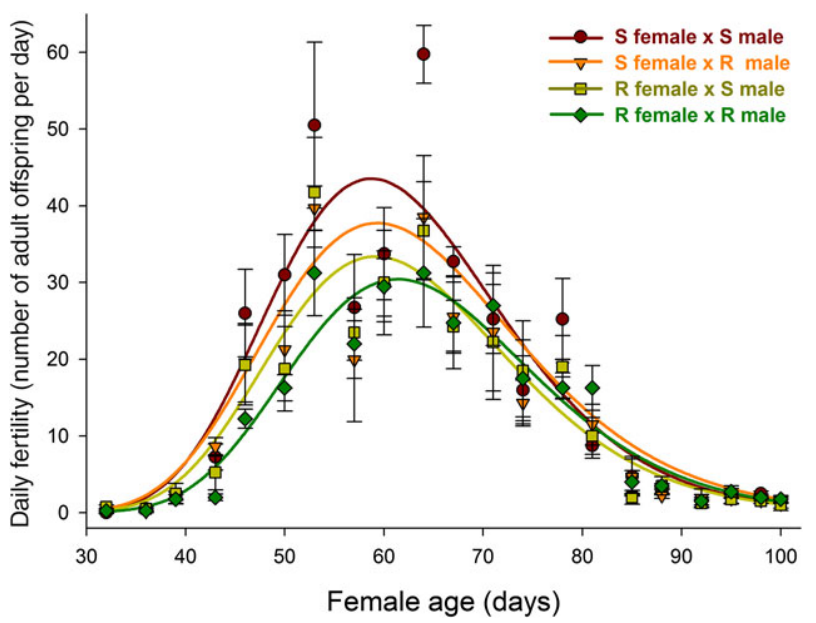

Figure 4. Non-cumulative fertility (number of adult offspring) resulting from the four possible matings involving a deltamethrin-susceptible and deltamethrin-resistant strains of the maize weevil (S. zeamais) [i.e. resistant female and male $(R \times R)$, susceptible female and male $(S \times S)$, resistant female and susceptible male $(R \times S)$ and susceptible female and resistant male $(S \times R)]$. Each symbol indicates the mean $( \pm S E)$ observed values of at least three replicates. The summary statistics for the regression curves are given in Table 3.

that produces (aggregation) pheromone], ${ }^{33-35}$ lending further credence to the occurrence of female choice rather than (precopulatory) male-male competition in the assortative mating detected in our experimental set-up. That said, male-male competition does seem to occur among grain weevils, where female-mounted males use their extended legs to fend off intruding males. ${ }^{35}$ The long mounting/coupling period observed in the maize weevil mating behaviour, and also in the related rice weevil, when a $1 \mathrm{~h}$ mating is enough for successful copulation, indicates male guarding behaviour. ${ }^{33,36,46}$ However, male-male competition among maize weevils does not seem to interfere with female choice, but potentially favours assortative mating, and size assortative mating in particular, in these species.

Size assortative mating is the most common mating pattern in natural animal populations, including arthropods. ${ }^{16,17}$ Therefore, the detection of size-related assortative mating in the maize weevil is not a surprise, although previously undetected. ${ }^{36}$ However, the previous study of mating behaviour and mate choice in maize weevil was performed with only two fairly distinct strains with different genetic backgrounds likely compromising the detection of such a pattern, particularly considering that the body mass was considered in absolute terms, not in relative terms in a dichotomous choice. Furthermore, size-directed female choice was significant only among insecticide-susceptible females, which are usually

Table 3. Summary statistics of non-linear regression analyses of the non-cumulative fertility curves (Fig. 4) for each mating type of the maize weevil S. zeamais [i.e. resistant female and male $(R \times R)$, susceptible female and male $(S \times S)$, resistant female and susceptible male $(R \times S)$ and susceptible female and resistant male $(S \times R)]$. All of the equation parameters are significant at $P<0.05$ by Student' $t$-test

\begin{tabular}{|c|c|c|c|c|c|c|c|c|}
\hline \multirow[b]{2}{*}{ Model } & \multirow[b]{2}{*}{ Mating type } & \multicolumn{3}{|c|}{ Parameter ( \pm SEM) } & \multirow[b]{2}{*}{$F_{2}$} & \multirow{2}{*}{$\begin{array}{l}\text { Degrees of freedom } \\
\text { (reg; error) }\end{array}$} & \multirow[b]{2}{*}{$P$} & \multirow[b]{2}{*}{$R^{2}$} \\
\hline & & $a$ & $b$ & c & & & & \\
\hline \multirow{4}{*}{$\begin{array}{l}\text { log normal } \\
\text { (three parameters) } \\
y=a \exp \left\{-0.5[\ln (x / b) / c]^{2}\right\}\end{array}$} & $\mathrm{S} \times \mathrm{S}$ & $43.55 \pm 2.64$ & $58.73 \pm 0.83$ & $0.20 \pm 0.01$ & 91.15 & $2 ; 81$ & $<0.001$ & 0.69 \\
\hline & $S \times R$ & $37.76 \pm 2.19$ & $59.32 \pm 0.85$ & $0.21 \pm 0.01$ & 91.93 & $2 ; 60$ & $<0.001$ & 0.75 \\
\hline & $R \times R$ & $30.44 \pm 1.64$ & $61.39 \pm 0.77$ & $0.20 \pm 0.01$ & 109.01 & $2 ; 81$ & $<0.001$ & 0.72 \\
\hline & $\mathrm{R} \times \mathrm{S}$ & $33.41 \pm 2.11$ & $59.16 \pm 0.88$ & $0.20 \pm 0.01$ & 81.63 & $2 ; 81$ & $<0.001$ & 0.67 \\
\hline
\end{tabular}


smaller than deltamethrin-resistant females, and favouring heavier males, which are usually resistant to deltamethrin based on our selection.

Sexual selection, assortative mating and mating preference vary not only among species but also within species, among populations, ${ }^{4}$ as seems to be the case for size assortative mating in the maize weevil. A previous study on the mating behaviour of maize weevil detected female choice, but not size assortative mating, ${ }^{36}$ and here we detected size assortative mating only among susceptible female weevils, reinforcing the within-species variation in this mating pattern. This finding is also indicative of a likely multimodal pattern of choice, where size is an important trait, but may not be the main one depending on the population. Association of highly heritable traits, such as size (or body mass) and insecticide or disease resistance, are potential candidate targets for sexual selection and intrasexual competition. ${ }^{4,16}$ Indeed, body mass seems to play a significant role in female preference, at least among some populations of maize weevil, likely associated with other untested morphological traits, chemical cues or behavioural traits. Nonetheless, this is not the case for insecticide resistance, which is rather an associated trait inadvertently favoured by female preference, and maybe also by male-male competition, and consequently by assortative mating.

The mating preference of insecticide-susceptible female weevils for heavier males, which are usually the deltamethrin-resistant ones in the pair offered for mating, leads to a size assortative pattern of mating that favours the evolution and spread of deltamethrin resistance alleles in the weevil population. However, deltamethrin resistance in the selected strain of maize weevil from our study exhibits an associated fitness cost impairing the reproductive output of the resistant insects. Such a fitness cost associated with insecticide resistance is a common assumption and of frequent occurrence, albeit not universal. ${ }^{48,49}$ This association allows the momentary suppression of use of this particular insecticide aimed at the re-establishment of susceptibility after a few generations as this trait will erode in the population. ${ }^{6,50,51}$

Curiously, the fitness cost detected in association with deltamethrin resistance in the maize weevil strain under scrutiny was negligible in males, and virtually undetectable when they crossed with susceptible females. Therefore, progeny production will not be compromised by the (susceptible) female preference for deltamethrin-resistant males from our study, compromising the management strategy indicated above and still favouring the evolution and spread of deltamethrin resistance alleles in the weevil population, a reason for management concern. The generality of such a trend among populations of the maize weevil and the potentially associated traits contributing to assortative mating in this pest species are issues worthy of future attention. This is so because they are likely to shed further light on insecticide resistance management and will assist in better recognising the limitations of the prevailing models for the evolution of insecticide resistance, again with management implications.

\section{ACKNOWLEDGEMENTS}

The financial support provided by the National Council of Scientific and Technological Development (CNPq), the CAPES Foundation and the São Paulo and Minas Gerais State Foundations of Research Aid (FAPESP and FAPEMIG) is greatly appreciated.

\section{REFERENCES}

1 Georghiou GP and Taylor CE, Genetic and biological influences in the evolution of insecticide resistance. J Econ Entomol 70:319-323 (1977).

2 Georghiou GP and Taylor CE, Operational influences in the evolution of insecticide resistance. J Econ Entomol 70:653-658 (1977).

3 Kokko H, Brooks R, Jennions MD and Morley J, The evolution of mate choice and mating biases. Proc R Soc Lond B 270:653-664 (2003).

4 Jones $A G$ and Ratterman NL, Mate choice and sexual selection: what have we learned since Darwin? Proc Natl Acad Sci USA 106(Suppl.): 10001 - 10008 (2009).

5 Reynolds JD and Gross MR, Costs and benefits of female mate choice: is there a Lek paradox? Am Nat 1136:230-243 (1990).

6 Roush RT and Mckenzie JA, Insecticide and acaricide resistance. Annu Rev Entomol 32:361 - 380 (1987).

7 Renton M, Shifting focus from the population to the individual as a way forward in understanding, predicting and managing the complexities of evolution of resistance to pesticides. Pest Manag Sci 69:171 - 175 (2013).

8 Stratonovitch P, Elias J, Denholm I, Slater R and Semenov MA, An individual-based model of the evolution of pesticide resistance in heterogeneous environments: control of Meligethes aeneus population in oilseed rape crops. PLoS ONE 9:e115631 (2014).

9 Rowland M, Activity and mating competitiveness of gamma $\mathrm{HCH} /$ dieldrin resistant and susceptible male and virgin female Anopheles gambiae and An. stephensi mosquitoes, with assessment of an insecticide-rotation strategy. Med Vet Entomol 5:207-222 (1991).

10 Berticat C, Boquien G, Raymond M and Chevillon C, Insecticide resistance genes induce a mating competition cost in Culex pipiens mosquitoes. Genet Res 79:41-47 (2002).

11 Platt N, Kwiatkowska RM, Irving H, Diabaté A, Dabire R and Wondji CS, Target-site resistance mutations ( $\mathrm{kdr}$ and $\mathrm{RDL}$ ), but not metabolic resistance, negatively impact male mating competiveness in the malaria vector Anopheles gambiae. Heredity 115:243-252 (2015).

12 Thornhill R, Sexual selection and parental investment in insects. Am Nat 110:153-163 (1976).

13 Jaffe K, Issa S, Daniels E and Haile D, Dynamics of the emergence of genetic resistance to biocides among asexual and sexual organisms. J Theor Biol 188:289-299 (1997).

14 Crowder DW, Rami Horowitz A, De Barro PJ, Liu SS, Showalter AM, Kontsedalov S et al., Mating behaviour, life history and adaptation to insecticides determine species exclusion between whiteflies. J Anim Ecol 79:563-570 (2010).

15 Morrow EH and Connallon T, Implications of sex-specific selection for the genetic basis of disease. Evol Applic 6:1208-1217 (2013).

16 Crespi BJ, Causes of assortative mating in arthropods. Anim Behav 38:980-1000 (1989).

17 Jones TM, Arnqvist G, McNamara KB and Elgar MA, Size-assortative pairing across three developmental stages in the Zeus bug, Phoreticovelia disparata. Behav Ecol Sociobiol 66:995-1003 (2012).

18 McNamara KB, Jones TM and Elgar MA, Female reproductive status and mate choice in the hide beetle, Dermestes maculatus. J Insect Behav 17:337-352 (2004).

19 Guedes RNC, Lima JG, Santos JP and Cruz CD, Resistance to DDT and pyrethroids in Brazilian populations of Sitophilus zeamais Motsch. (Coleoptera: Curculionidae). J Stored Prod Res 31:145-150 (1995).

20 Fragoso DB, Guedes RNC and Rezende ST, Glutathione S-transferase detoxification as a potential pyrethroid resistance mechanism in the maize weevil, Sitophilus zeamais. Entomol Exp Applic 109:21-29 (2003).

21 Ribeiro B, Guedes RN, Oliveira E and Santos J, Insecticide resistance and synergism in Brazilian populations of Sitophilus zeamais (Coleoptera: Curculionidae). J Stored Prod Res 39:21 - 31 (2003).

22 Pereira CJ, Pereira EJG, Cordeiro EMG, Della Lucia TMC, Tótola MR and Guedes RNC, Organophosphate resistance in the maize weevil Sitophilus zeamais: magnitude and behavior. Crop Prot 28:168-173 (2009).

23 Braga LS, Corrêa AS, Pereira EJG and Guedes RNC, Face or flee? Fenitrothion resistance and behavioral response in populations of the maize weevil, Sitophilus zeamais. J Stored Prod Res 47:161-167 (2011).

24 Corrêa A S, Pereira EJG, Cordeiro EMG, Braga LS and Guedes RNC, Insecticide resistance, mixture potentiation and fitness in populations of the maize weevil (Sitophilus zeamais). Crop Prot 30:1655-1666 (2011). 
25 Pimentel MAG, Faroni LRDA, Guedes RNC, Sousa AH and Tótola MR, Phosphine resistance in Brazilian populations of Sitophilus zeamais Motschulsky (Coleoptera: Curculionidae). J Stored Prod Res 45:71-74 (2009).

26 Corrêa AS, Tomé HVV, Braga LS, Martins GF, De Oliveira LO and Guedes RNC, Are mitochondrial lineages, mitochondrial lysis and respiration rate associated with phosphine susceptibility in the maize weevil Sitophilus zeamais? Ann Appl Biol 165:137-146 (2014).

27 Guedes RNC, Oliveira EE, Guedes NMP, Ribeiro B and Serrão JE, Cost and mitigation of insecticide resistance in the maize weevil, Sitophilus zeamais. Physiol Entomol 31:30-38 (2006).

28 Oliveira EE, Guedes RNC, Tótola MR and De Marco P, Competition between insecticide-susceptible and -resistant populations of the maize weevil, Sitophilus zeamais. Chemosphere 69:17-24 (2007).

29 Ribeiro B, Guedes RNC, Corrêa AS and Santos CT, Fluctuating asymmetry in insecticide-resistant and insecticide-susceptible strains of the maize weevil, Sitophilus zeamais (Coleoptera: Curculionidae). Arch Environ Contam Toxicol 53:77-83 (2007).

30 Araújo RA, Guedes RNC, Oliveira MGA and Ferreira GH, Enhanced activity of carbohydrate- and lipid-metabolizing enzymes in insecticide-resistant populations of the maize weevil, Sitophilus zeamais. Bull Entomol Res 98:417-424 (2008).

31 Araújo RA, Guedes RNC, Oliveira MGA and Ferreira GH, Enhanced proteolytic and cellulolytic activity in insecticide-resistant strains of the maize weevil, Sitophilus zeamais. J Stored Prod Res 44:354-359 (2008).

32 Lopes KVG, Silva LB, Reis AP, Oliveira MGA and Guedes RNC, Modified $\alpha$ amylase activity among insecticide-resistant and -susceptible strains of the maize weevil, Sitophilus zeamais. J Insect Physiol 56: 1050-1057 (2010)

33 Walgenbach CA, Phillips JK, Faustini DL and Burkholder WE, Maleproduced aggregation pheromone of the maize weevil, Sitophilus zeamais, and interspecific attraction between three Sitophilus species. J Chem Ecol 9:831-841 (1983).

34 Phillips JK, Walgenbach CA, Klein JA, Burkholder WE, Schmuff NR and Fales HM, $\left(R^{*}, S^{*}\right)$-5-Hydroxy-4-methyl-3-heptanone male-produced aggregation pheromone of Sitophilus oryzae (L.) and S. zeamais Motsch. J Chem Ecol 11:1263-1274 (1985).

35 Walgenbach CA and Burkholder WE, Mating behavior of the maize weevil, Sitophilus zeamais (Coleoptera: Curculionidae). J Econ Entomol 80:578-583 (1987).
36 Guedes NMP, Guedes RNC, Campbell JF and Throne JE, Mating behavior and reproductive output in insecticide-resistant and -susceptible strains of the maize weevil (Sitophilus zeamais). Ann Appl Biol in press.

37 Halstead DGH, External sex differences in stored-products Coleoptera. Bull Entomol Res 54:119-134 (1963).

38 Tolpo NC and Morrison EO, Sex determination by snout characteristics of Sitophilus zeamais Motschulsky. Texas J Sci 17:122-124 (1965).

39 Trematerra P, Fontana F and Mancini M, Analysis of development rates of Sitophilus zeamais (L.) in five cereals of the genus Triticum. J Stored Prod Res 32:315-322 (1996).

40 Fragoso DB, Guedes RNC and Peternelli LA, Developmental rates and population growth of insecticide-resistant and susceptible populations of Sitophilus zeamais. J Stored Prod Res 41:271 - 281 (2005).

41 Carvalho GA, Vieira JL, Haro MM, Corrêa AS, Ribon AOB, de Oliveira LO et al., Pleiotropic impact of endosymbiont load and co-occurrence in the maize weevil Sitophilus zeamais. PLoS ONE 9:e111396 (2014).

42 Robertson JL and Preisler HL, Pesticide Bioassays with Arthropods. CRC Press, Boca Raton, FL (1992).

43 Yates $\mathrm{F}$, Contingency tables involving small numbers and the $\mathrm{X} 2$ test. J R Stat Soc Suppl 1:217-235 (1934).

44 Corrêa AS, Tolledo J, Pereira EJG and Guedes RNC, Bidirectional selection for body mass and correlated response of pyrethroid resistance and fitness in Sitophilus zeamais. J Appl Entomol 135:285-292, 135 (2011).

45 Arnaud $L$ and Haubruge $E$, Insecticide resistance enhances male reproductive success in a beetle. Evolution 56:2435-2444 (2002).

46 Campbell JF, Fitness consequences of multiple mating on female Sitophilus oryzae L. (Coleoptera: Curculionidae). Environ Entomol 34:833-843 (2005).

47 Gilotra SK, Reproductive potentials of dieldrin-resistant and susceptible populations of Anopheles albimanus Wiedemann. Am J Trop Med Hyg 14:165-169 (1965).

48 Coustau C, Chevillon C and ffrench-Constant R, Resistance to xenobiotics and parasites: can we count the cost? Trends Ecol Evol 15:378-383 (2000).

49 Kliot $A$ and Ghanim M, Fitness costs associated with insecticide resistance. Pest Manag Sci 68:1431-1437 (2012).

50 Mallet J, The evolution of insecticide resistance: have the insects won? Trends Ecol Evol 4:336-340 (1989).

51 McKenzie JA and Batterham P, The genetic, molecular and phenotypic consequences of selection for insecticide resistance. Trends Ecol Evol 9:166-169 (1994). 